\title{
Images of Plasma Disruption Effects in the Tokamak Fusion Test Reactor
}

\author{
Ricardo J. Maqueda and Glen A. Wurden, Member, IEEE
}

\begin{abstract}
Fast-framing imaging of visible radiation from magnetically confined plasmas has lately become a useful tool for both machine operation and physics studies. Using an intensified, commercial Kodak Ektapro imaging system, the effects of a plasma disruption were observed in the Tokamak Fusion Test Reactor (TFTR). The high-energy "runaway" electrons created soon after the disruption collide with the plasma facing components damaging this surface and producing a shower of debris that traverses the toroidal vessel and "falls" over the inner bumper limiter.
\end{abstract}

Index Terms - Digital systems, magnetic confinement, optical imaging, plasmas, tokamaks.

A FAST-FRAMING visible imaging system was used on the Tokamak Fusion Test Reactor (TFTR) during its last one and a half years of operation [1]. This imaging system, based on a Kodak Ektapro intensified imager coupled to a Kodak Ektapro EM1012 motion analyzer, ${ }^{1}$ was typically operated at 1000 frames per second with exposures as short as $10 \mu$ s. Each digital (full) frame is composed of $239 \times 192$ pixels and has 8-bit resolution.

The system is capable of running at up to $6000 \mathrm{~Hz}$ by splitting the image and rearranging the multiplexing of the 8-bit digitizers; for example, at the maximum rate only $1 / 6$ of the full image (i.e., $239 \times 32$ pixels) can be recorded. The RAM memory available in the system can store up to 1638 full images, resulting in a coverage of almost $1.64 \mathrm{~s}$.

Considering the characteristics of TFTR's imaging system: fast-framing $(\geq 1 \mathrm{kHz})$, intensified, and digital recording, it is easy to see why systems like this one have become a useful tool in magnetic confinement fusion experiments for both machine operation and physics studies. In particular, the intensification allows the use of narrowband interference filters tuned to particular radiation lines from impurities or fuel. The Kodak imaging system described here has also been used at the Alcator C-Mod tokamak of the Massachusetts Institute of Technology (and to image lightning bolts [2]). A similar system, although not intensified, is being used in START, a spherical torus of UKAEA (Culham).

All of the Kodak equipment was located in TFTR's test cell basement. The imager itself was mounted on one of TFTR's periscopes beneath the machine, consequently allowing the torus to be viewed from a midplane viewing port [3]. A fiberoptic GPIB interface was used across the $\sim 200 \mathrm{~m}$ between

Manuscript received June 24, 1998; revised November 2, 1998. This work was supported by United States DoE under Contracts W-7405-ENG-36 and DE-AC02-76-CH03073.

The authors are with Los Alamos National Laboratory, Plasma Physics Group, Los Alamos, NM 87545 USA (e-mail: maqueda@lanl.gov).

Publisher Item Identifier S 0093-3813(99)02602-8.

${ }^{1}$ Eastman Kodak Company, Motion Analysis System Division, 11633 Sorrento Valley Road, San Diego, CA 92121 USA. the Kodak equipment and an Intel-based control PC that was placed in TFTR's control room annex. All processes in the control PC, including storage of digital images as TIFF files, were executed under a LabView virtual instrument developed specifically for this application. Selected image sequences have been compressed into MPEG clips that can be seen through the World Wide Web at: http://lib-www.lanl.gov/lapubs/00418586.pdf, together with associated waveforms. The images were synchronized to the experiment by a hardware trigger pulse that was directly given to the Kodak motion analyzer by TFTR's main control system.

Tokamak plasma discharges occasionally end with a disruption: a sudden loss of equilibrium and confinement. Some of these disruptions are caused by MHD perturbations that stop rotating with the plasma column, lock on to the wall (i.e., field error), and grow in amplitude without saturation [4]. In Fig. 1 the effects of a disruption caused by a rotating $m=4 n=1$ mode that locks to the vessel wall are shown (discharge 103681). This disruption takes place $\sim 2.425 \mathrm{~s}$ after discharge initiation. The images in this figure were obtained at a sampling rate of $2 \mathrm{kHz}$, although every other image (i.e., 1 ms spacing) is shown. As a reference, the tiles on the bumper limiter are nominally $10 \mathrm{~cm} \times 10 \mathrm{~cm}$ in size.

In this example a $\sim 0.6 \mathrm{MA}$ toroidal current remains after the disruption. This current is mostly carried by runaway electrons created by the strong electric fields present during the quench of the toroidal (ohmic) plasma current [4]. These high energy ( $\sim 20 \mathrm{MeV}$ ) electrons collide into plasma facing components causing damage. In Fig. 1 the damage manifests itself by a (horizontal) shower of debris that "falls onto" the bumper limiter above the device midplane. Although not as spectacular as the example shown here, flying debris is almost always seen after disruptions. The diameter of the hot-glowing flying particles is estimated to be up to $1 \mathrm{~cm}$ and their speed is of the order of $100 \mathrm{~m} / \mathrm{s}$. It is speculated that the debris seen in these images is part of the Faraday shield for the RF heating antenna (IBW) that was located approximately opposite to the section of bumper limiter shown and that was noticed missing a few weeks later.

\section{REFERENCES}

[1] R. J. Hawryluk, S. Batha, W. Blanchard, M. Beer, M. G. Bell, R. E. Bell, H. Berk, S. Bernabei, M. Bitter, B. Breizman, N. L. Bretz, R. Budny, C. E. Bush, J. Callen, R. Camp, S. Cauffman, Z. Chang, C. Z. Cheng, D. S. Darrow, R. O. Dendy, W. Dorland, H. Duong, P. C. Efthmion, D. Ernst, N. J. Fisch, R. Fisher, R. J. Fonck, E. D. Frederickson, G. Y. Fu, H. P. Furth, N. N. Gorelenkov, B. Grek, L. R. Grisham, G. W. Hammett, G. R. Hanson, H. W. Herrmann, M. C. Hermann, K. W. Hill, J. Hogan, J. C. Hosea, W. A. Houlberg, M. Hughes, R. A. Hulse, D. L. Jassby, F. C. Jobes, D. W. Johnson, R. Kaita, S. Kaye, J. S. Kim, M. Kissick, A. V. Krasilnikov, H. Kugel, A. Kumar, B. Leblanc, F. M. Levinton, C. Ludescher, R. P. Majeski, J. Manickam, D. K. Mansfield, E. Mazzucato, J. McChesney, D. C. McCune, K. M. McGuire, D. M. 


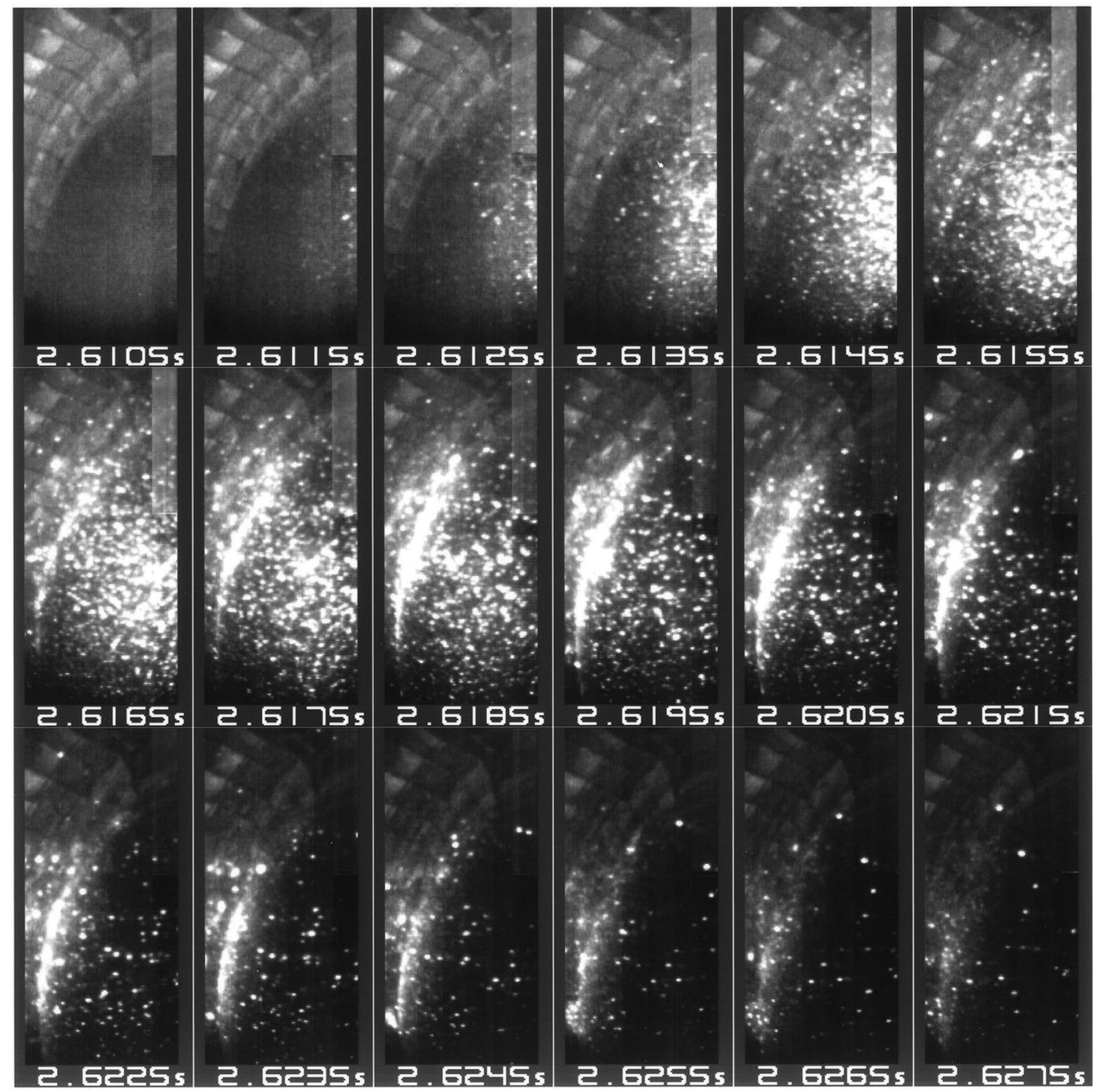

Fig. 1. Sequence of images of the inner third of the toroidal plasma column with the armored inner wall of the plasma chamber shown on the left. (This inner wall is the bumper limiter of TFTR.) The inside of the torus' outer wall is not shown. The debris from the disruption enters the field of view from the right at $\sim 2.6135 \mathrm{~s}$ and flies to the left until it strikes the inner wall, starting at about $2.6165 \mathrm{~s}$. The images were obtained with $30 \mu \mathrm{s}$ exposure in white visible light (i.e., no interference filter).

Meade, S. S. Medley, R. Mika, D. R. Mikkelsen, S. V. Mirnov, D. Mueller, A. Nagy, G. A. Navratil, R. Nazikian, M. Okabayashi, H. K. Park, W. Park, S. F. Paul, G. Pearson, M. P. Petrov, C. K. Phillips, M. Phillips, A. T. Ramsey, M. H. Redi, G. Rewoldt, S. Reznik, A. L. Roquemore, J. Rogers, E. Ruskov, S. A. Sabbagh, M. Sasao, G. Schilling, J. Schivell, G. L. Schmidt, S. D. Scott, I. Semenov, C. H. Skinner, T. Stevenson, B. C. Stratton, J. D. Strachan, W. Stodiek, E. Synakowski, H. Takahashi, W. Tang, G. Taylor, M. E. Thompson, S Von Goeler, A. Von Halle, R. T. Walters, R. White, R. M. Wieland, M. Williams, J. R. Wilson, K. L. Wong, G. A. Wurden, M. Yamada, V.
Yavorski, K. M. Young, L. Zakharov, M. C. Zarnstorff, and S. J. Zweben, "Fusion plasma experiments on TFTR: A 20 year retrospective," Phys. Plasmas, vol. 5, pp. 1577-1589, May 1998.

[2] G. A. Wurden and D. O. Whiteson, "High-speed plasma imaging: A lightning bolt," IEEE Trans. Plasma Sci., vol. 24, pp. 83-84, Feb. 1996.

[3] S. S. Medley, D. L. Dimock, S. Hayes, D. Long, J. L. Lowrance, V. Mastrocola, G. Renda, M. Ulrickson, and K. M. Young, "Periscopecamera system for visible and infrared imaging diagnostics on TFTR," Rev. Sci. Instrum., vol. 56, pp. 1873-1884, Oct. 1985.

[4] J. Wesson, Tokamaks. New York: Oxford Univ. Press, 1997, ch. 7. 